Robert J. Hudson MD FRCPC

\section{Apnoea and uncon- sciousness after apparent recovery from alfentanil-supplemented anaesthesia}

d' alfentanil a été administrée pour une période de 3,25 h à une femme de 45 ans subissant une gastrectomie. Du naloxone 0,16 mg IV fut administré et ceci a restauré la ventilation spontanée et la conscience. Ce cas démontre que l'apnée et l'inconscience peuvent aussi survenir après réveil apparent avec l'alfentanil. Le personnel de la salle de réveil doit être conscient de ce phénomème. Une détection précoce permet le traitement avant que l'apnée survienne. les patients ayant reçu des narcotiques en supplément doivent être surveillés par un capnographe etlou un saturomètre de pouls dans la période postopératoire.

Alfentanil is a newly available synthetic narcotic that has a shorter elimination half-time than its older analogues, fentanyl and sufentanil. ' This suggests that postoperative respiratory depression might be less likely after alfentanil. We report a case of recurrent unconsciousness and apnoea after apparent recovery from alfentanil-supplemented anaesthesia.

\section{Case report}

A 45-year-old, 70-kg female was scheduled for a partial gastrectomy for peptic ulcer disease refractory to medical therapy. She had essential hypertension, treated with atenolol $100 \mathrm{mg}$, hydrochlorthiazide $50 \mathrm{mg}$ and amiloride $5 \mathrm{mg}$ daily. She was also taking perphenazine $4 \mathrm{mg}$ and clomipramine $50 \mathrm{mg}$ daily for depression. The last dose of atenolol was given the morning of surgery; her other medications were discontinued 12 to $48 \mathrm{hr}$ before surgery. She was given ranitidine $150 \mathrm{mg} P O$ the evening before and the morning of surgery. Lorazepam $2 \mathrm{mg} \mathrm{SL}$ was given for preoperative sedation. Cefazolin $1 \mathrm{~g}$ and metronidazole $500 \mathrm{mg}$ were given for prophylaxis against infection.

Prior to induction of anaesthesia, fentanyl $75 \mu \mathrm{g}$ IV and 100 per cent oxygen were administered. Anaesthesia was induced with alfentanil $50 \mu \mathrm{g} \cdot \mathrm{kg}^{-1}$ and thiopentone 175 $\mathrm{mg}$, and succinylcholine $100 \mathrm{mg}$ was given to facilitate tracheal intubation. Anaesthesia was maintained with nitrous oxide 70 per cent (inspired), supplemented by 
isoflurane $0-0.5$ per cent (inspired) and a continuous infusion of alfentanil. Haemodynamic responses to surgery that were not controlled by isoflurane 0.5 per cent (inspired) were treated with small bolus doses of alfentanil, $7.5 \mu \mathrm{g} \cdot \mathrm{kg}^{-1}$, and/or increasing the infusion rate to a maximum of $1.5 \mu \mathrm{g} \cdot \mathrm{kg}^{-1} \cdot \mathrm{min}^{-1}$. The doses of alfentanil and isoflurane were adjusted according to clinical signs of the depth of anaesthesia, including heart rate, blood pressure, and pupil size. Continually, attempts were made to decrease the alfentanil infusion rate to minimize the total dose, so that several times during surgery the alfentanil infusion was temporarily discontinued. Metocurine-pancuronium (4:1 mixture) was used for muscle relaxation. The alfentanil infusion was stopped prior to closure of the peritoneum. The neuromuscular blockade was reversed during closure of the anterior abdominal wall. Adequacy of reversal was confirmed by visual and tactile assessment of the "train-of-four." The patient began to breathe spontaneously at 22-24 breaths $\cdot \mathrm{min}^{-1}$. A bolus of alfentanil, $5 \mu \mathrm{g} \cdot \mathrm{kg}^{-1}$, was given. This decreased the respiratory rate to 12 breaths $\cdot \mathrm{min}^{-1}$. The inhalational anaesthetics were discontinued, and the trachea was extubated in the operating room, at which time her respiratory rate was approximately 20 breaths $\cdot \mathrm{min}^{-1}$. Throughout surgery, during emergence from anaesthesia, and after extubation pulse oximetry indicated that the $\mathrm{SaO}_{2}$ was greater than 94 per cent. The total dose of alfentanil was $9.6 \mathrm{mg}$, or $137 \mu \mathrm{g} \cdot \mathrm{kg}^{-1}$.

The patient was admitted to the recovery room three hours and 15 minutes after induction of anaesthesia. At that time, she was drowsy but easily arousable and moving all extremities purposefully. Her heart rate was 78 beats $\cdot \mathrm{min}^{-1}$, blood pressure was $120 / 90 \mathrm{mmHg}$, and her respiratory rate was 14 breaths $\cdot \mathrm{min}^{-1}$. Oxygen, $5 \mathrm{~L}$. $\mathrm{min}^{-1}$, was administered. Nine minutes after admission to the recovery room, the patient had a respiratory arrest. Ventilation by mask with 100 per cent oxygen was begun. The patient did not respond to vigorous rubbing over the sternum, and placement of a pulse oximeter indicated that the $\mathrm{SaO}_{2}$ was 50 per cent, which improved with artificial ventilation. Her heart rate and blood pressure were 80 beats $\cdot \mathrm{min}^{-1}$ and $80 / 60 \mathrm{mmHg}$, respectively. There was some muscle tone in the upper extremities, but there was no frank rigidity. Naloxone $0.16 \mathrm{mg}$ IV was administered, which rapidly resulted in return of spontaneous respiration at 20 breaths $\cdot \mathrm{min}^{-1}$, and an increase in the level of consciousness. The heart rate increased to 85 beats $\cdot \mathrm{min}^{-1}$, and the blood pressure increased to $136 / 80$ $\mathrm{mmHg}$. Fifteen minutes later, the patient was fully awake and complaining of pain. She was given morphine $3 \mathrm{mg}$ IV over the next 30 minutes. The remainder of her postoperative course was uncomplicated.

\section{Discussion}

The rapidity with which this easily arousable patient became unresponsive and apnoeic is unusual, but not unprecedented. Several similar cases of apnoea and recurrent unconsciousness after apparent recovery from sufentanil have been reported. ${ }^{2-4}$ Recurrent depression of the slope of the $\mathrm{CO}_{2}$ response curve occurs postoperatively in the majority of patients given fentanyl. ${ }^{5}$ Recurrent respiratory depression has also been observed after initial recovery from alfentanil. ${ }^{6-8}$ Although the residual effects of premedication, other anaesthetics or neuromuscular blocking drugs can also cause respiratory depression, the dramatic response to naloxone implicates narcotics as the cause of our patient's respiratory arrest.

Postoperative respiratory depression may be due to administration of excessive doses of narcotic intraoperatively. However, we do not feel that the dose given in this case was inappropriate. The infusion rate of alfentanil was continually adjusted downward so as to maintain a satisfactory depth of anaesthesia with the lowest possible dose. The patient was admitted to the recovery room 3.25 $\mathrm{hr}$ after induction of anaesthesia, after receiving a total of $137 \mu \mathrm{g} \cdot \mathrm{kg}^{-1}$ of alfentanil. For comparison, Ausems et al. used alfentanil as the sole supplement to nitrous oxide in patients undergoing upper abdominal surgery. ${ }^{9} \mathrm{~A}$ mean total dose of more than $500 \mu \mathrm{g} \cdot \mathrm{kg}^{-1}$ was required for procedures lasting an average of $3.25 \mathrm{hr}$. Presumably, our patient required a lower dose of alfentanil because of the concomitant administration of isoflurane.

Recurrent respiratory depression after apparent recovery from alfentanil has been previously reported. ${ }^{6-8}$ In these cases, the total doses of alfentanil ranged from 156 $\mu \mathrm{g} \cdot \mathrm{kg}^{-1}$ over 93 minutes $^{6}$ to $278 \mu \mathrm{g} \cdot \mathrm{kg}^{-1}$ over 110 min. $^{8}$ These doses are considerably larger than the dose given to our patient. Furthermore, in all of these cases, the alfentanil infusion rate was apparently predetermined, with no, or few, attempts to titrate the dose according to individual patients' responses.

Secondary peaks of the plasma concentration of fentanyl ${ }^{10-13}$ and sufentanil ${ }^{14}$ during the elimination phase have been observed in several pharmacokinetic studies. These peaks are often contemporaneous with increases in muscular activity which occur after emergence from anaesthesia and reversal of neuromuscular blockade. Skeletal muscle is an important storage site for fentanyl. ${ }^{15}$ It appears that increased perfusion of muscle can elute enough of these lipophilic narcotics to cause severe, recurrent respiratory depression. The clinical course of our patient suggests that this can also occur after apparent recovery from alfentanil. The relative frequency and severity of this phenomenon after administration of different narcotics are unknown. It is probably dose- 
related, in that enough narcotic must be sequestered in muscle to cause subsequently a substantial increase in the plasma concentration.

The ventilatory depressant effects of narcotics are enhanced by loss of consciousness. ${ }^{16}$ Stimulation by suctioning the airway, extubation of the trachea, and transfer to the recovery room may antagonize the effects of opioids and delay the onset of respiratory depression. However, the complete lack of response to vigorous rubbing over the sternum suggests that lack of stimulation, by itself, cannot explain the recurrence of unconsciousness and respiratory arrest observed in this case.

The administration of both fentanyl and alfentanil requires explanation. The original intent had been to use alfentanil. At that time, in our hospital, alfentanil had to be requisitioned on a case-by-case basis. Because of a change in the schedule, it appeared that alfentanil would not be available, so the case was begun using fentanyl. The alfentanil was obtained shortly thereafter, and we continued with it. In view of the relative amounts of alfentanil and fentanyl administered, it is exceedingly unlikely that the fentanyl contributed importantly to the recurrence of unconsciousness and apnoea $3.5 \mathrm{hr}$ after its administration.

This case illustrates that, even after careful titration to minimize the total dose of opioid, severe respiratory depression can recur after recovery from alfentanil. This should be considered in planning perioperative care of all patients for whom a narcotic-supplemented anaesthetic technique is chosen. Earlier detection may permit treatment before apnoea occurs. All recovery room personnel should be cognizant of the potential for recurrent apnoea and unconsciousness after apparent recovery from narcotics. Furthermore, we suggest that all patients given narcotic-supplemented anaesthetics be monitored by capnography and/or pulse oximetry in the immediate postoperative period.

\section{References}

1 Mather LE. Clinical pharmacokinetics of fentanyl and its newer derivatives. Clin Pharmacokinet 1983; 8: 422-46.

2 Goldberg M, Ishak S, Garcia C, McKenna J. Postoperative rigidity following sufentanil administration. Anesthesiology 1985; 63: 199-201.

3 Chang J, Fish KJ. Acute respiratory arrest and rigidity after anesthesia with sufentanil: a case report. Anesthesiology 1985; 63: 710-1.

4 Robinson $D$. Respiratory arrest after recovery from anaesthesia supplemented with sufentanil. Can J Anaesth 1988; 35: 101-6.
5 Becker LD, Paulson BA, Miller RD, Severinghaus JW, Eger EI II. Biphasic respiratory depression after fentanyl-droperidol or fentanyl alone used to supplement nitrous oxide anesthesia. Anesthesiology 1976; 44: 291-6.

6 Jaffe RS, Coalson D. Recurrent respiratory depression after alfentanil administration. Anesthesiology 1989; 70: 151-2.

7 Lamarche $Y$, Martin $R$, Grenier $Y$. Continuous infusion of alfentanil for surgery. Can Anaesth Soc J 1984; 31 : S64-5.

8 Sebel PS, Lalor JM, Flynn PJ, Simpson BA. Respiratory depression after alfentanil. Br Med J 1984; 289: 1581-2.

9 Ausems ME, Hug CC, Stanski DR, Burm AL. Plasma concentrations of alfentanil required to supplement nitrous oxide anesthesia for general surgery. Anesthesiology $1986 ; 65$ : 362-73.

10 McQuay HJ, Moore RA, Paterson GMC, Adam AP. Plasma fentanyl concentrations and clinical observations during and after operation. Br J Anaesth 1979; 51: 543-50.

11 Stoeckel H, Hengstmann JH, Schüttler J. Pharmacokinetics of fentanyl as a possible explanation for recurrence of respiratory depression. Br J Anaesth 1979; 51: 741-5.

12 McClain DA, Hug CC Jr. Intravenous fentanyl kinetics. Clin Pharmacol Ther 1980; 28: 106-14.

13 Hudson RJ, Thomson IR, Cannon JE, Friesen RM, Meatherall $R C$. Phamacokinetics of fentanyl in patients undergoing abdominal aortic surgery. Anesthesiology $1986 ; 64: 334-8$.

14 Hudson RJ, Bergstrom RG, Thomson IR, Sabourin MA, Rosenbloom $M$, Strunin $L$. Pharmacokinetics of sufentanyl in patients undergoing abdominal aortic surgery. Anesthesiology 1989; 70: 426-31.

15 Hug CC, Murphy MR. Tissue redistribution of fentanyl and termination of its effects in rats. Anesthesiology 1981; 55: 369-75.

16 Catley DM, Thornton C, Jordan C, Lehane JR, Royston D, Jones JG. Pronounced, episodic oxygen desaturation in the postoperative period: its association with ventilatory pattem and analgesic regimen. Anesthesiology 1985; 63: $20-8$. 